\title{
Editorial: Emerging Technologies and Associated Scientific Advancements for CCUS Deployment
}

\author{
Greeshma Gadikota ${ }^{1 *}$, Anne M. Gaffney ${ }^{2}$, Rafael M. Santos ${ }^{3}$ and Lunbo Duan ${ }^{4}$ \\ 'School of Civil and Environmental Engineering, Smith School of Chemical and Biological Engineering, Cornell University, \\ Ithaca, NY, United States, ${ }^{2}$ Energy, Environment, and Science and Technology Division, Idaho National Laboratory, \\ Idaho Falls, ID, United States, ${ }^{3}$ School of Engineering, University of Guelph, Guelph, ON, Canada, ${ }^{4}$ School of Energy and \\ Environment, Southeast University, Nanjing, China
}

Keywords: $\mathrm{CO}_{2}$ removal, carbon mineralization, $\mathrm{CO}_{2}$ utilization, $\mathrm{CO}_{2}$ activation, energy and resources

\section{Editorial on the Research Topic}

\section{Emerging Technologies and Associated Scientific Advancements for CCUS Deployment}

The urgency in meeting ambitious targets for removing carbon from our emissions and air calls for rapid scientific and technological advancements across several scales - ranging from developing molecular-scale insights into the reactivity of $\mathrm{CO}_{2}$, to advancing thermodynamically favored reaction pathways for carbon removal, and evaluating the scalability of technologies for $\mathrm{CO}_{2}$ capture, utilization, storage, and removal. In this context, our special issue titled, Emerging Technologies and Associated Scientific Advancements for CCUS deployment, features a unique compilation of studies that discuss pathways, strategies, and technologies for closing the carbon cycle and removing carbon from our emissions and air that are timely and necessary.

Decarbonizing our energy supply and defossilizing our chemical processes are essential for meeting our energy and resource needs in a sustainable manner. Approaches to activate $\mathrm{CO}_{2}$ for conversion to fuels, chemicals, and materials using chemical and electrochemical pathways are being actively investigated with the aim of closing the carbon cycle. One of the less explored approaches to activate $\mathrm{CO}_{2}$ involves the use of nuclear irradiation. One of the key advantages of harnessing nuclear energy is the lack of intermittency in operation compared to solar and wind energy resources, and the ability to utilize different forms of radiation to activate $\mathrm{CO}_{2}$. In this context, Ramirez-Corredores et al. describe pathways for chemically upgrading anthropogenic $\mathrm{CO}_{2}$ to basic chemicals and fuels using nuclear irradiation. The ability to directly use energy resources to transform matter to meet our chemical needs is unique to nuclear energy resources. $\alpha, \beta$, and $\gamma$ radiation emerging from nuclear resources can be uniquely harnessed to produce the next generation of chemicals by activating $\mathrm{CO}_{2}$. Advancements in small modular nuclear reactors will allow us to realize these pathways for producing the next generation of fuels and chemicals using anthropogenic $\mathrm{CO}_{2}$, thus allowing us to close the carbon cycle while meeting our energy needs. This approach is a less explored but highly transformative pathway to explore $\mathrm{CO}_{2}$ activation.

Articles in this special issue discuss pathways to remove $\mathrm{CO}_{2}$ from our emissions, such as carbon mineralization, that are complimentary to and compatible with the advancement of $\mathrm{CO}_{2}$ capture, utilization, and storage technologies. Carbon mineralization involves converting $\mathrm{CO}_{2}$ to inorganic calcium or magnesium carbonates, and it can be harnessed and accelerated to produce re-useable carbonate-cemented products, as reviewed by Hills et al.. To successfully implement carbon mineralization technologies at scale, the development and application of doi: 10.3389/fenrg.2021.649126 integrated frameworks and decision support tools is essential, as decribed by Bourgeois et al. 
A perspective on the state of novel $\mathrm{CO}_{2}$ utilization technologies is provided by Warsi et al. Parallels that can be drawn from the development of two successfully developed hardware-heavy technologies, the solar and the automobile industries, to advance $\mathrm{CO}_{2}$ utilization technologies are discussed. Drawing on historical case studies from other markets and start-ups, including Bergen Carbon Solutions as described by Sareen and Sagmo, is crucial for the commercialization of $\mathrm{CO}_{2}$ utilization technologies that have the potential to constitute a multi-billion dollar commodity market. This unique collection of articles is intended to raise awareness associated with decarbonizing our energy supply and defossilizing our chemical processes for a sustainable energy and resource future.

\section{AUTHOR CONTRIBUTIONS}

All authors listed have made a substantial, direct and intellectual contribution to the work, and approved it for publication.

Conflict of Interest: The authors declare that the research was conducted in the absence of any commercial or financial relationships that could be construed as a potential conflict of interest.

Copyright (c) 2021 Gadikota, Gaffney, Santos and Duan. This is an open-access article distributed under the terms of the Creative Commons Attribution License (CC BY). The use, distribution or reproduction in other forums is permitted, provided the original author(s) and the copyright owner(s) are credited and that the original publication in this journal is cited, in accordance with accepted academic practice. No use, distribution or reproduction is permitted which does not comply with these terms. 